\title{
DIGITALCOMMONS
}

@WAYNESTATE-

Wayne State University

Civil and Environmental Engineering Faculty

Research Publications

Civil and Environmental Engineering

$4-28-2020$

\section{Load Truncation Approach for Development of Live Load Factors for Bridge Rating}

\author{
Sasan Siavashi \\ Wayne State University, sasan.siavashi@wayne.edu \\ Christopher D. Eamon \\ Wayne State University, eamon@eng.wayne.edu
}

Follow this and additional works at: https://digitalcommons.wayne.edu/ce_eng_frp

Part of the Civil Engineering Commons, and the Transportation Engineering Commons

\section{Recommended Citation}

Siavashi, S. and Eamon, C. D. 2020. "Load truncation approach for development of live load factors for bridge rating." J. Bridge Eng. 25 (7): 04020039. https://doi.org/10.1061/(ASCE)BE.1943-5592.0001559.

This Article is brought to you for free and open access by the Civil and Environmental Engineering at DigitalCommons@WayneState. It has been accepted for inclusion in Civil and Environmental Engineering Faculty Research Publications by an authorized administrator of DigitalCommons@WayneState. 
1 Load Truncation Approach for Development of Live Load Factors for Bridge Rating

2 Sasan Siavashi ${ }^{1}$ and Christopher D. Eamon ${ }^{2}$

3 Abstract

4 Various local governments have developed state-specific vehicular live load factors for bridge

5 rating. However, a significant computational demand is often associated with such an effort. This

6 is due to the large size of the weigh-in-motion (WIM) databases frequently used in the procedure.

7 In this study, a method is proposed that can significantly reduce the computational cost of the

8 analysis, while still maintaining reasonable accuracy. The proposed approach develops

9 approximate live load random variable statistics by truncating the WIM database based on gross

10 vehicle weight, then a complete reliability analysis is conducted to develop new live load factors

11 that meet AASHTO-specified rating standards. Two WIM databases, one based on typically legal

12 vehicles and another based on unusually heavy vehicles, are considered for evaluation. Results of

13 the proposed approach are compared to an exact assessment as well as to a simplified method

14 suggested by AASHTO. It was found that the proposed approach may provide very large

15 reductions in computational cost with minimal loss of accuracy, whereas significant inaccuracies

16 were found with the existing simplified approach.

\section{Author Keywords:}

19 Weigh-in-motion, WIM, Gross Vehicle Weight, Bridge, Load model, Rating, Design

20
1. Department of Civil \& Environmental Engineering, Wayne State University, Detroit, MI, USA (corresponding author); sasan.siavashi@wayne.edu

2. Associate Professor, Department of Civil \& Environmental Engineering, Wayne State University, Detroit, MI, USA; eamon@eng.wayne.edu 


\section{Introduction}

In the US, bridge load rating is required by the US Department of Transportation (DOT)

to assure that structures within each state inventory are sufficiently safe for vehicular traffic.

31 Bridge rating procedures are specified in the Manual for Bridge Evaluation (MBE) (AASHTO

32 2018), where rating for design, legal, and permit loads is discussed. Bridge rating has been based

33 on an assessment of structural reliability since 2003 with the publication of the Manual for

34 Condition Evaluation and Load and Resistance Factor Rating (LRFR) of Highway Bridges

(AASHTO 2003). The MBE was later released in 2008, replacing the initial LRFR specifications

as well as the alternative 1998 Manual for Condition Evaluation of Bridges (based on allowable stress and load factor rating (LFR), which was not reliability-based, but still allowed for use to assess structures designed under older, non-reliability based design provisions (AASHTO 1998).

The purpose of the LRFR version was to provide a more consistent level of safety than that

40 achieved under the previous LFR procedure. As part of LRFR calibration, the appropriate

41 vehicular live load statistics used in the reliability assessment to establish live load factors for

42 rating were developed. These factors were later again revised in 2011 (Sivakumar and Ghosn 2011)

43 using weigh-in-motion (WIM) data from truck traffic collected in 2005 and 2006 from six states

44 including New York, Mississippi, Indiana, Florida, and California. The recalibrated MBE rating

45 process was formulated based on a 5-year return period for load rating to achieve a minimum target reliability index $(\beta)$ of 1.5 for any particular girder, with an average target level of 2.5 across the

47 bridge inventory.

As expected, significant improvement in load modeling over previous versions was

49 achieved due to the use of current (at the time) WIM data. However, the WIM data collected from 
51 not included in the MBE calibration effort. Therefore, various states have initiated efforts to

52 develop unique live load models that better represent traffic data specific to their region. Some of

53 these states include Oregon (Pelphrey and Higgins 2006), New York (Ghosn et al. 2011; Anitori

54 et al. 2017), Michigan (Eamon et al. 2014; Eamon and Siavashi 2018), Missouri (Kwon et al.

55 2010), and Illinois (Fu et al. 2019) where the live load factors for bridge design and rating were

56 developed based on state-specific WIM data. Similar efforts to better characterize vehicle load

57 effects based on WIM data were conducted by Lee and Souny-Slitine 1998 (Texas) and Tatabai et

58 al. 2009 (Wisconsin).

Although substantially conservative load modeling can be conducted with minimal effort,

60 the cost associated with conservatively rating existing bridges is significantly higher than

61 conservatively designing new structures. While conservative designs may lead to slightly larger

62 component sizes or reinforcement levels, conservative rating may lead to unnecessary posting,

63 rehabilitation, or replacement. Posted bridges that restrict traffic limit commercial vehicles from

64 fully utilizing the transportation network, which may negatively affect local economies. Therefore,

65 DOTs prefer to limit bridge posting as much as possible while not jeopardizing the level of safety.

Various models have been proposed to develop load models for bridge design and rating

67 (Miao and Chan 2002; O'Brien et al. 2010; Nowak and Rakoczy 2013, etc.). Although these

68 various methods of live load model development using WIM data may differ substantially in

69 approach, they each share a significant drawback if accurate results are desired: high

70 computational cost. This is primarily a result of the large database of vehicle records typically used

71 for load effect assessment, which can often range from tens to hundreds of millions of vehicles

72 (Sivakumar and Ghosn 2011, Nowak and Rakoczy 2013; Eamon et al. 2014, Eamon and Siavashi

73 2018). Each truck record in the database, representing a unique multi-axle configuration, is 
74 typically analyzed for the maximum load effects that it causes across multiple bridge spans and in

75 some cases different bridge types. At present, a considerable amount of WIM data is available

76 from numerous states. Although utilizing a large database may increase load modeling accuracy,

77 it correspondingly increases computational cost. Although not theoretically problematic, this

78 computational cost may render WIM-based solutions undesirable, if not practically inaccessible,

79 depending on the time and resources available.

Various studies has proposed the use of gross vehicle weight (GVW) as a surrogate for a

81 more rigorous analysis of vehicular load effects, such as for development of simplified methods to

82 estimate load factors (Fu and Hag-Elsafi 2000; Moses 2001), as well as an indicator of the

83 magnitude of load effect (O'Brien and Enright 2012), among others. In this study, a different

84 approach is proposed, where the objective is to develop an approximate live load random variable

85 based on selectively eliminating the large majority of vehicles from the WIM database based on

86 GVW. Using the approximate live load random variable, a full reliability assessment is then

87 conducted to establish live load factors for rating. To illustrate the proposed approach, an example

88 state-specific analysis is conducted to determine live load factors for the Strength I limit state (i.e.

89 normal use vehicles, such as legal and routine permit) within the framework of the AASHTO 90 MBE.

\section{WIM Data Considered}

92 Prior to load effect analysis, a WIM database for consideration must be identified. For 93 evaluation of the method proposed in this study, data from twenty WIM stations in the State of 94 Michigan were used. The WIM stations selected record data at a frequency of $1,000 \mathrm{~Hz}$, a sampling 95 rate that can accurately capture vehicle configurations and relative vehicle positioning. Data were 96 collected with quartz piezoelectric sensor systems permanently embedded in and flush to the 
97

98

99

100

101

roadway surface. The system consists of weight sensors and inductive loops placed on either side of the sensors. The loop before the sensors detects a vehicle and activates the WIM system, while the loop after the sensors tracks the time that vehicle axles cross between the loops, information which is used to determine vehicle speed and axle spacing. Each lane has its own sensor system, which are linked together to record simultaneous multiple lane events. WIM stations are monitored and periodically calibrated to test vehicles of known axle weight and configuration by DOT personnel to ensure accuracy. During this calibration process, possible dynamic effects are removed such that the pseudo-static axle weights are captured. Sixteen of these sites are on major interstate routes (I-94, I-69, I-75, and I-96) while four are on lower-volume state highways (US127, US-2, and M-95). The data were collected for 34 months from February 2014 to January 2017 (excluding April and May 2014, which were unavailable). The average daily truck traffic (ADTT) varied from approximately 360 to 16,500 with ten stations greater than 5,000, five stations with roughly 3,500 , three near 1,500 , and two with approximately 400 ADTT. Each WIM station automatically filters noncritical lightweight vehicles with GVW less than $67 \mathrm{kN}$ from the database, resulting in approximately 101 million vehicle records. However, due to possible errors in WIM data collection, additional data filtering was used to remove potentially erroneous records from the database. These filtering criteria included feasible limitations on axle spacing, weight, speed, and length (Eamon and Siavashi 2018). A typical frequency histogram of GVW is primarily bi-modal, with peak frequencies at approximately $334 \mathrm{kN}$ and $156 \mathrm{kN}$, which represent the most common loaded and unloaded 5-axle truck weights in Michigan. Nearly all sites are represented with similar multi-modal frequency plots, though peaks shift somewhat as a function of differences in local traffic density. Approximately $80 \%$ of trucks at all sites were of the five-axle (3S2) type. To further confirm the reasonableness of the WIM data, various checks were implemented as recommended 
120 in NCHRP 683 (Sivakumar et al. 2011), such as comparing the GVW frequency histograms, mean

121 and modal axle spacing, GVW, and axle weights to generally expected values (Eamon and

122 Siavashi 2018). These quality checks reduced the database to approximately 89.5 million. The

123 database was then further analyzed to consider only state (Michigan) legal and routine (annual or

124 extended) permit vehicles which are used by Michigan Department of Transportation (MDOT) for

125 Strength I limit state evaluation (i.e. normal use of the bridge) within the legal load rating

126 framework. As discussed in further detail below, Strength I live load statistics are correspondingly

127 based on this pool of legal and routine permit vehicles, although no specific limit is imposed on

128 the probability density model and thus the possibility of sampling a vehicle exceeding the legal

129 limit in the subsequent reliability analysis is maintained. Following the MBE calibration approach,

130 it is assumed that even heavier vehicles (i.e. special permit and potentially extreme illegal

131 overloads) are to be accounted for in the Strength II limit state. A summary of the criteria used to

132 categorize a record as MI-Legal or Extended Permit vehicles (MI-LEP) is given in Table 1.

133 Approximately 88.9 million vehicles fell into this category. As Michigan has unusually high legal

134 vehicle weights, up to approximately twice the Federal limit for some configurations, a vehicle

135 pool representative of most other states that follow the Federal limit was also developed. This

136 alternative database was created by imposing more restrictive limits based on the Code of Federal

137 Regulations Part 658.17 (1994), which represents a simplified version of the axle weight and

138 spacing rule commonly known as the "Bridge Formula". This is labeled in Table 1 as the

139 "Simplified CFR" category. Approximately 78.4 million vehicles fell into this group. From the

140 different data pools as described above, load effects (maximum moments and shears) were

141 calculated by incrementing the measured vehicles across hypothetical simple bridge spans (from

142 6-60 $\mathrm{m}$ in length) in increments of $300 \mathrm{~mm}$. 
144 Correlation of Vehicle Parameters and Load Effect

Once load effects are determined for the entire vehicle database of interest, the typical 146 approach used for load factor development is to form the cumulative distribution function (CDF)

147 for a particular bridge span and load effect of interest. Then, various approaches are available to 148 estimate the statistical parameters (typically limited to the first two statistical moments; mean and 149 standard deviation) from the CDF needed to characterize the maximum load effect as a random 150 variable representing a return period of interest, which is taken as 5 years for Strength I rating in 151 AASHTO MBE (AASHTO 2018). This live load random variable is then used in a reliability 152 analysis to obtain the required rating live load factors, as described in more detail below. In most 153 procedures used to develop the live load random variable statistical parameters, only the very upper 154 tail of the load effect CDF is used, which might range from $20 \%$ to less than $1 \%$ of the data, 155 depending on the approach (Moses 2001; Sivakumar et al. 2011; Nowak and Rakoczy 2013, 156 Eamon et al. 2014, Eamon and Siavashi 2018). As such, the large majority of vehicle load effects 157 that are calculated are not needed. This represents a considerable waste of computational effort. 158 For example, to calculate vehicle moments for a single bridge span of $18 \mathrm{~m}$ using the database of 15989 million MI-LEP vehicle records discussed above required approximately 45 hours on a modern 160 personal computer (Intel Core i7 2.7/3.6 GHz CPU with $32 \mathrm{~GB}$ of RAM). Realize this analysis 161 must be repeated for various different bridge spans, different bridge types in some cases, and for 162 shear effects as well, resulting in a rather substantial computational effort requirement. If the 163 number of vehicles considered could be reduced to only those that will form the upper tail of the 164 load effect CDF used for the live load model, say, to $1 / 10^{\text {th }}$ of the original database, this time would 
165 be similarly reduced to approximately $1 / 10^{\text {th }}$ of that originally required, representing a substantial 166 savings of computational effort.

With regard to computational demand, here it should be noted that there are three types of 168 vehicle positioning scenarios to be considered: a single vehicle on the bridge; multiple vehicles in 169 a single lane ("following" vehicles); and vehicles in more than one lane (multiple-lane load 170 effects). In practice, single and following vehicle effects are combined to construct a database of 171 single lane load effects, then two types of load effect analysis are conducted: one for the single 172 lane loaded case and the second for the multiple lane loaded case. Although a bridge may have 173 many lanes of traffic, the MBE calibration, and hence the comparisons presented in this study, 174 consider up to two-lane effects, which encompass the most probable multi-lane events and for 175 which most WIM data are available. Both analyses are required for all hypothetical structures 176 considered to develop final live load factors as there is often no clear pattern, in terms of bridge 177 span and girder spacing, as to which type of load effect (i.e. one-lane or two-lane) will govern. 178 With regard to computational effort, the single-lane, single vehicle load effects are of most 179 concern, as these typically make up the vast majority of load effects generated. Although 180 proportions vary with bride span, ADTT, location, and classification method, various studies have 181 found that single vehicle effects make up greater than $95 \%$ of load effects in most instances 182 (Sivakumar et al. 2011, Eamon et al. 2014, Eamon and Siavashi 2018). For example, for the MI183 LEP database mentioned above, considering the 6-60 $\mathrm{m}$ span range, the ratio of multiple presence 184 vehicles to single vehicles was approximately 1:70 to 1:1000 (with longer spans having a greater 185 likelihood of multiple presence). Such results are typical. Therefore, this study is focused on 186 reducing the computational effort only related to single vehicle load effects, although it would be 
187 possible to apply the proposed method to multi-lane data as well in the same manner that it is 188 applied here to one lane load effects.

To reduce computational effort, the relationship between single vehicle load effect and 190 directly available vehicle parameters within the WIM data can be studied, to determine if such a parameter can be used to include only the vehicles which will have significant impact on the load 192 effect statistics. This approach could thus eliminate the need to compute load effects for the large majority of vehicles. An obvious parameter to consider is GVW. However, although it may appear 194 intuitive that only the heaviest trucks are important, the effectiveness of using GVW as a direct 195 surrogate for load effect is quantitatively unknown. One complication is the effect of vehicle 196 length, where heavier vehicles are often longer, and may produce lower load effects than a lighter, 197 shorter vehicle. Another factor is bridge span length, where the effect of vehicle length may be 198 expected to become less important as span length increases. As such, the vehicle parameters 199 selected for consideration were: GVW; length; number of axles; GVW/length; and GVW x length. 200 These parameters are either directly available from the WIM data or readily calculated from two 201 available parameters with minimal computational effort. The correlation coefficient $(\rho)$ of each of 202 these parameters to load effect was computed across various span lengths for the MI-LEP and 203 Simplified CFR vehicle databases described above. Results for moment effects are shown in 204 Figures 1 and 2. Shear results are nearly identical and are thus not shown.

As shown in the figures, in general, as span length increases, the correlation between load 206 effect and all considered parameters except GVW / length increases. GVW is shown to have the 207 highest correlation, with values varying from about 0.9 to nearly 1.0 for both vehicle databases. 208 As these values of $\rho$ are high, the use of GVW to eliminate a large portion of vehicles from 209 consideration appears promising. In fact, a simplified method to estimate live load factors for 
210 rating based on GVW is already given in the MBE, based on NCHRP 454 (Moses 2001), and is

211 taken as (for single lane loading):

$212 \gamma_{L}=1.8\left[\frac{W^{*}+t_{(A D T T)} \sigma^{*}}{120}\right] \geq 1.80$

Eq. 1

213 where $W^{*}$ and $\sigma^{*}$ are the mean truck weight and standard deviation of the top 20 percent of the

214 vehicle sample (kips), and $t_{(A D T T)}$ is a fractile value appropriate for the maximum expected loading

215 event, taken as 4.9, 4.5, and 3.9 for ADTT values of 5000, 1000, and 100, respectively. The

216 accuracy of this existing AASHTO method, however, is not clearly documented. The effectiveness

217 of the AASHTO approach, as well as the alternative approach proposed in this study, is later 218 quantified.

219 To clarify the difference between the "exact", AASHTO, and proposed approaches for live 220 load factor development, first consider the exact procedure. In the exact method, load effects from

221 all vehicles in the appropriate WIM database are first computed. As noted above, a different set of 222 load effects is needed for each span length considered in the analysis. Once all load effects are 223 computed for a given span, the CDF of load effects for that span is formed. For rating, from this $224 \mathrm{CDF}$, the mean maximum load statistics for a 5-year return period are developed. As noted above, 225 alternative procedures are available to do this. An investigation of these various possibilities is 226 beyond the focus of this study. However, a common method that was used in the reliability 227 calibration of the MBE (Sivakumar and Ghosn 2011) as well as in subsequent studies (Sivakumar 228 et al. 2011, Eamon et al. 2014, Eamon and Siavashi 2018) models the live load using extreme 229 value theory. This model can be accurately used if the extreme (high) values of the load effect 230 CDF well-fit a normal distribution. If so, the mean maximum load effect $\left(\bar{L}_{\text {max }}\right)$ and its standard 231 deviation $\left(\sigma_{L \text { max }}\right)$ are given as: 
$232 \quad \bar{L}_{\max }=\mu_{N}+\frac{0.5772157}{\alpha_{N}}$

Eq. 2

$233 \sigma_{L \max }=\frac{\pi}{\sqrt{6} \alpha_{N}}$

Eq. 3

234 where

$235 \mu_{N}=\bar{x}+\sigma\left(\sqrt{2 \ln (N)}-\frac{\ln (\ln (N))+\ln (4 \pi)}{2 \sqrt{2 \ln (N)}}\right)$

Eq. 4

$236 \quad \alpha_{N}=\frac{\sqrt{2 \ln (N)}}{\sigma}$

Eq. 5

237 In these expressions, $N$ is the total number of trucks expected during the return period (i.e. in 5 238 years) and $\bar{x}$ and $\sigma$ within Eqs. 4 and 5 are found from the slope $(m)$ and intercept $(n)$ of a line fit

239 to the upper tail of the CDF when plotted on normal probability paper (i.e. when the vertical axis

240 is taken as the inverse standard normal CDF), where parameters $\bar{x}$ and $\sigma$ are given by $\bar{x}=-\frac{n}{m}$ and

$241 \sigma=\frac{1-n}{m}-\bar{x}$, respectively. For illustration, example CDFs for simple moments considering the

242 very heaviest vehicles (top $0.1 \%$ ) of the MI-LEP database for spans of 6-60 $\mathrm{m}$ and accompanying

243 best-fit regression lines suitable for use in Eqs. 2-5 are shown in Figure 3. The resulting vehicle

244 load statistics $\left(\bar{L}_{\max }\right.$ and $\left.\sigma_{L \max }\right)$ are then used along with other load effect uncertainties, as

245 discussed further below, to form a random variable for live load which can be used in reliability

246 analysis to determine appropriate live load factors for rating.

In contrast, the AASHTO approach (Eq. 1), represents a substantial computational savings

248 from the exact approach, as no load effects need to be calculated, nor does any reliability analysis

249 need to be conducted; only the mean and standard deviation of the top $20 \%$ of GVW of vehicles

250 in the database are computed. As quantified later, however, as perhaps expected, some accuracy

251 concerns exist with this simplified approach. Here it should be noted that although Eq. 1 appears

252 in the MBE, it was not used in the latest calibration effort and does not necessarily produce load

253 factors representing the currently intended level of reliability. Rather, it was the exact procedure 
254 (i.e. using "all" WIM data) that was used to determine target reliability levels and set 255 corresponding load factors. As discussed in the MBE, although Eq. 1 is offered as an alternative 256 to reduce computational effort for site-specific cases (as further discussed below), intended 257 reliability targets are achieved with the exact approach, and it was thus recommended for state258 wide use (AASHTO 2018; Sivakumar and Ghosn 2011).

The alternative approach proposed in this study follows the same framework of the exact 260 approach. The only difference is the number of vehicles used to calculate load effects that are used 261 to form the CDF. Rather than use the entire vehicle database, load effects are computed only from 262 the heaviest vehicles. Here, regardless of the size of the reduced database, the fundamental 263 requirements of the extrapolation procedure described above are maintained in all cases; i.e. a best264 fit regression line is fit to the upper linear tail of data (where the length of the tail may vary, 265 depending on the proportion of data on the CDF that are linear in standard normal space), then 266 Eqs. 2-5 are used to estimate vehicle load effect statistics. Because other vehicle characteristics 267 such as vehicle length, axle spacing, and axle weight influence load effect, basing the load effect 268 CDF only on maximum GWV vehicles is an approximation. The effectiveness of this 269 approximation, based on what proportion of maximum GWV vehicles are considered, is quantified 270 later in this study. It should be noted that the reliability analysis (which requires a separate analysis 271 for each girder type, spacing, and span length considered) used in the exact and proposed 272 approaches actually involves an insignificant amount of effort, in terms of computational time, 273 beyond the AASHTO approach (less than several seconds for the entire reliability analysis for all 274 cases). Rather, it is the calculation of load effects needed to form the CDF which requires the vast 275 majority of computational effort. 


\section{Reliability Analysis}

For the exact and proposed procedures, a reliability analysis is required to determine rating load factors. These factors, the ultimate product of interest, will be used to compare the accuracy of the three alternate methods considered (exact, AASHTO, proposed). For comparison, the analysis was conducted for bridges which make up the majority of most state inventories: those that are constructed of composite steel and prestressed concrete I-girders, prestressed concrete box beams (both spread and side-by-side), and reinforced concrete girders. Simple span structures of these girder types were analyzed with spans from 6 to $60 \mathrm{~m}$ at increments of $6 \mathrm{~m}$ for all girders except for reinforced concrete, which is limited to 30 meters. Girder spacing was varied from 1.2 to $3.6 \mathrm{~m}$ at $0.6 \mathrm{~m}$ increments, while for side-by-side box beams, two widths $(0.9 \mathrm{~m}$ and $1.2 \mathrm{~m})$ were considered. Bridges were assumed to support a $230 \mathrm{~mm}$ thick reinforced concrete deck, 65 $\mathrm{mm}$ wearing surface, and additional typical nonstructural items (primarily barriers and diaphragms) relevant to dead-load calculation. Thus, considering all combinations of length (10) and girder spacing (5) increments results in 50 geometries each for prestressed concrete, steel, and spread box beam bridge types; 25 for reinforced concrete; and 20 side-by-side box beams, for 195 cases. The range of these geometries and types covers nearly all girder bridges in the state of Michigan as well as other state inventories. Although the consideration of alternative designs, such as non-girder type bridges, longer spans, curved or skewed decks, and other features are important, such structures represent somewhat unique cases not directly considered in the MBE calibration, and are thus beyond the scope of the comparisons presented here. Moreover, it is not currently possible to assess potential differences between the methods compared in this study considering many of these bridge features, since WIM data are generally taken from stations placed on the roadway rather than directly on bridge decks. Thus, the effects that many interesting 
300 features of bridge geometry (such as curvature, skew, etc.) might have on traffic pattern are 301 typically not available. However, the authors would currently propose no adjustment to the 302 method proposed in these circumstances.

304 live load. Dead load includes prefabricated $\left(D_{p}\right)$ site-cast $\left(D_{s}\right)$ and deck wearing surface $\left(D_{w}\right)$ 305 components, while live load consists of vehicle live load $\left(L_{\max }\right)$ and dynamic load $\left(I_{M}\right)$. In addition, 306 uncertainty in the distribution of vehicular live load to an individual girder is considered $(D F)$. 307 Bias factor (ratio of mean to nominal value) and coefficient of variation (COV) of these random 308 variables are presented in Table 2.

309 The live load random variable statistical parameters are not only a function of the 310 uncertainty in projected maximum vehicle load effect, characterized here by coefficient of

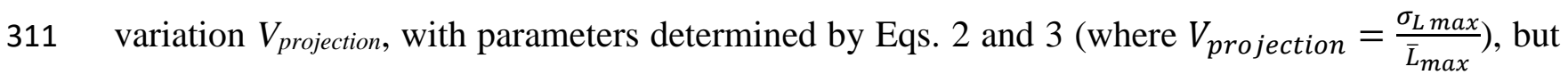
312 other uncertainties as well. These uncertainties include those of site location $\left(V_{\text {site }}\right)$, characterizing 313 the variation in mean maximum load effect from one site to another; the dynamic load effect, $\left(V_{I M}\right)$, 314 taken as 9\% for one lane effects (Sivakumar et al. 2011); the uncertainty in WIM data collection 315 at a particular site $\left(V_{\text {data }}\right)$, taken as $2 \%$ for the database considered (Eamon and Siavashi 2018); 316 and uncertainty in vehicular live load distribution to the girder $\left(V_{D F}\right)$, which varies as a function 317 of girder type as shown in Table 2 (Sivakumar et al. 2011). The resulting COV of total live load 318 effect can be thus approximated as:

$319 V_{\text {max } L}=\sqrt{V_{\text {projection }}^{2}+V_{\text {site }}^{2}+V_{\text {data }}^{2}+V_{I M}^{2}+V_{D F}^{2}} \quad$ Eq.6

320 This final value was found to vary from $0.16-0.30$, depending on the bridge type and vehicle 321 database considered. 
With the exception of live load, all random variable statistical parameters used in the

323

324

325

326

327

328

329

330

331

332

333

334 AASHTO LRFD (Nowak 1999) and MBE calibrations (Sivakumar and Ghosn 2011) are used in this study. To be consistent with the reliability model used in these previous calibration efforts, it is also assumed that girder resistance is lognormal whereas the sum of load effects is taken as normally distributed.

Once random variables are defined, the general limit state function $g_{i}$ for each bridge girder $i$ can be written as:

$g_{i}=R-\left(D_{p}+D_{s}+D_{w}\right)-D F\left(L_{\max }+I_{M}\right)$ Eq. 7

with random variables $D_{p}, D_{s}, D_{w}, D F, I_{M}$, and $L_{\max }$ defined above. Limit states are formed for simple span load effects for moment and shear.

The minimum requirements of acceptability need to be identified in order to establish nominal values for girder resistance $R$ to be used in the reliability analysis. In the case of rating, the rating factor is the metric used to determine the minimum level of acceptability (i.e. if rating factor is $\geq 1.0$, no traffic restriction is required). In the MBE, rating factor (RF) is defined as:

$$
R F=\frac{\phi R_{n}-1.25 D C-1.5 D W}{\gamma_{L L}(L L+I M)}
$$

In Eq. 8 , resistance factor $\phi$ varies as a function of girder type and failure mode; $R_{n}$ is the nominal resistance of the component; $D C$ and $D W$ are respectively the dead loads of the structure and the wearing surface; $L L$ is the rating vehicle live load effect; $I M$ is specified as $0.33^{*} L L$; and $\gamma_{L L}$ is the rating vehicle load factor. Note that the parameters given in Eq. 8 can be calculated according to the MBE specifications based on the bridge geometry and other code-specified factors. The uncertainties in these parameters are represented as random variables in the limit state function. In particular, uncertainties in nominal resistance $R_{n}$ and weight of the wearing surface 
$344 D W$ in Eq. 8. are represented by directly corresponding random variables $R$ and $D_{w}$ in Eq. 7. The

345 remaining dead load effect $D C$ in Eq. 8 is represented as the sum of two random variables $D_{p}$ and

$346 D_{s}$, and the live and dynamic load effects on the girder $L L$ and $I M$ are represented by random

347 variables $L_{\max }$ and $I_{M}$, respectively, in addition to a random variable accounting for the uncertainty

348 in load distribution to the girder, $D F$.

349 Considering legal and routine permit vehicles, the MBE considers two limits for target

350 girder reliability index $\beta$ : a minimum of $\beta=1.5$ for any girder as well as an average of $\beta=2.5$ across

351 all girders in the inventory. Both limits are applied to the specific case when $\mathrm{RF}=1.0$ which

352 represents the boundary of acceptability (i.e. just before traffic requires restriction). Therefore, by

353 setting $\mathrm{RF}=1.0$ in Eq. 8 and solving for $R_{n}$, the required nominal resistance at these target

354 reliability levels can be determined as follows:

355

$R_{n}=(1 / \phi)\left(1.25 D C+1.5 D W+\gamma_{L L}(L L+I M)\right)$

Eq. 9

In Eq. $9, R_{n}$ can be found from the dead load $(D C, D W)$ and live load $\left(\gamma_{L L}, L L, I M\right)$ effects.

357 Once $R_{n}$ is found, using the bias factors $\lambda$ shown in Table 2, the mean value $\bar{R}$ of the girder 358 resistance random variable $R$ can be calculated $\left(\bar{R}=\lambda \times R_{n}\right)$. As a result, the reliability index 359 associated with the limits state given by Eq. 7 can be computed. Note that, as typical for code 360 calibration efforts, the target reliability indices developed for the MBE (i.e. $\beta=1.5,2.5$ ) are 361 notional values calculated based on various simplifying and often highly conservative 362 assumptions, and are used for calibration purposes only. That is, the corresponding theoretical 363 failure probabilities (i.e. $p_{f}=\Phi(-\beta)$ ) should not be thought to represent actual bridge girder safety 364 levels. 
As mentioned earlier, this study concerns reducing the computational effort required to develop a live load model using WIM data while maintaining an acceptable level of accuracy. Developing a live load model may involve forming a new nominal rating vehicle and associated load effect $(L L)$, new live load factors for existing rating vehicles $\left(\gamma_{L L}\right)$, or both. Regardless of the approach taken, in this process, the total live load effect needed to be produced by the rating model $\left(\gamma_{L L}(L L+I M)\right)$ begins as an unknown. However, since the target reliability index limits are known (minimum of 1.5 and average of 2.5), the minimum value of $\gamma_{L L}(L L+I M)$ needed to produce an $R_{n}$ (and in particular, the mean value of $R$ ) that will satisfy the reliability target can be established. For convenience, the quantity $\gamma_{L L}(L L+I M)$ is referred to as the required load effect (RLE) in this study. In other words, RLE is the total load effect required by the live load rating model such that for any girder, when $\mathrm{RF}=1$, a minimum reliability index of 1.5 for any girder, with an average of 2.5, is met. Note that the RLE is a deterministic factor used to represent the total live load effect in the AASHTO rating equation (Eqs. 8, 9); it is not itself a random variable nor does it appear in the limit state function (Eq. 7), although uncertainties in load components $L L$ and $I M$ within the RLE are represented by individual random variables $L_{\max }$ and $I_{M}$ in the reliability analysis.

The reliability process is summarized as follows. First, based on values used for similar bridges considered in the previous reliability-based AASHTO code calibration efforts, nominal and mean (using the bias factors given in Table 2) values for dead load random variables $\left(D_{p}, D_{s}\right.$, $\left.D_{w}\right)$ and live load distribution factor $(D F)$ are calculated for a selection of typical bridge designs.

Second, the mean value of $R$, needed for reliability analysis, is expressed as $\bar{R}=\lambda \mathrm{x} R_{n}$, where $R_{n}$ is given by Eq. 9 and bias factor $(\lambda)$ given in Table 2 for the type of girder and failure mode considered. Note that $R_{n}$, and as a result $\bar{R}$, is a function of the unknown RLE value $\left(\gamma_{L L}(L L+I M)\right)$. 
Then, by setting the required reliability target to 1.5 for a given girder and considering the limit state function given by Eq.7, reliability index becomes a function of random variables $R, D_{p}$, $D_{s}, D_{w}, D F, I_{M}$, and $L_{\max }$ within Eq. 7 (where the precise relationship depends on the specific reliability analysis method chosen) Note that the mean girder resistance $\bar{R}$ remains a function of the unknown RLE. Finally, since the reliability index is known in the calculation of $\beta$, the RLE, 393 which is the only unknown, can be solved for. Therefore, the live load effect that meets the minimum reliability target and needed to be produced by the rating live load model (RLE) can be 395 established. From all results, the average reliability index is then computed to check this second 396 requirement $\left(\beta_{\text {ave }} \geq 2.5\right)$.

Due to the large number of bridges considered in this study, the reliability analysis was 398 conducted using the closed form first-order, second moment (FOSM) procedure, such that reliability index $(\beta)$ can be computed directly. The FOSM method assumes all random variables 400 are normal, which typically produces conservative assessments of reliability when resistance is 401 lognormal as in this study. However, Eamon et al. (2016) found that when reliability index 402 approaches 1.5, no significant difference exists between the FOSM and exact solution when the 403 limit state function and random variable parameters discussed above are considered. For 404 verification, a sample of girder reliability indices were computed with Monte Carlo Simulation 405 (MCS) with $1 \times 10^{6}$ simulations. It was found that the indices estimated with the FOSM approach 406 within $1 \%$ of the "exact" MCS values. For other problem types, alternative efficient reliability 407 algorithms can be considered (e.g. Acar et al. 2010). 
410 results of the exact approach using all vehicle data, as well as results of the AASHTO simplified 411 procedure.

\section{Effect of Data Reduction on Live Load Random Variable Statistical Parameters}

The purpose of the proposed approach is to reduce computational effort by computing load

414 effects for only a portion of the total vehicle database. A key issue to be addressed is how much

415 of the database can be practically removed while maintaining acceptably accurate results.

416 As discussed earlier, reducing the amount of data used to generate load effects will alter the

417 statistics of the live load random variable used in the reliability analysis needed to develop live 418 load factors for rating. Altering the data pool will affect the following statistical parameters: the 419 mean maximum live load effect $\left(\bar{L}_{\max }\right)$; coefficient of variation of the mean maximum load $420\left(V_{\text {projection }}\right)$; and the coefficient of variation with respect to WIM site location $\left(V_{\text {site }}\right)$; see Eqs. 6 421 and 7.

423 of vehicle data were removed such that the top 50, 20,10, 5, and 1 percent of single vehicle records 424 by GVW were retained. The load effects from these reduced single vehicle pools were then 425 calculated, and combined with all load effects constituting multiple vehicles in the same lane (i.e. 426 the "following" vehicle effects) to produce reduced databases of single lane load effects, as is 427 typically done. Recall from the discussion above that the following vehicle load effects, as well as 428 multiple-lane load effects generally account for only a very small proportion of the total load 429 effects, and thus these are not of interest in this study for consideration of alteration to reduce 430 computational effort. Once the reduced single lane load effects were calculated, the three affected

431 live load random variable statistics $\left(\bar{L}_{\text {max }}, V_{\text {projection }}, V_{\text {site }}\right)$ were similarly recomputed and used 432 to determine $V_{\max L}$ (Eq. 6), the total variation in live load effect. $V_{\max L}$ results for the reduced 
433 datasets are shown in Figures 4 and 5 for MI-LEP vehicles and are compared to the unreduced 434 database (“All”). Note that for construction of these figures (but not in subsequent reliability 435 calculations, where the exact values are used), from the range of possible values for $V_{D F}$ given in 436 Table $2, V_{D F}$ is taken as the minimum possible in all cases $(0.11$, which actually only corresponds 437 to the shortest $6 \mathrm{~m}$ span which allows for the resulting $V_{\max L}$ value to become most sensitive to 438 changes in the potentially altered parameters $V_{\text {projection }}$ and $V_{\text {site }}$.

439 As shown in the figures, for all data considered, $V_{\max } L$ decreases as span increases. This 440 result is typical (Nowak 1999, Sivakumar and Ghosn 2011, Kamjoo and Eamon 2018), and occurs 441 because load effects on smaller spans are more sensitive to variations in truck axle spacing and 442 weights. Consistent across all span lengths, however, for both moment and shear, $V_{\max L}$ was found 443 to slightly increase as the dataset is reduced. This is a result of a combination of a decreasing $444 V_{\text {projection }}$ and increasing $V_{\text {site }}$ as the data are reduced, with the increase in $V_{\text {site }}$ slightly 445 dominating. Here $V_{\text {projection }}$ decreases for a particular site because there is less variability in the 446 remaining data as the wider range of (lighter) load effects are removed. Conversely, $V_{\text {site }}$ increases 447 because removing these lighter vehicles, which are common to all sites, emphasizes differences in 448 the remaining heavy vehicles between sites due to local traffic patterns (for example, one site may 449 be close to a gravel pit or an industrial center, resulting in a certain type of heavy vehicle and 450 accompanying load effects not reflected at another site). However, the resulting difference in $V_{\max }$ $451 \quad L$ is so small (with a typical increase factor in $V_{\max L}$ of 1.01 and maximum increase factor of 1.04) 452 that it is inconsequential. Similar results were observed for the simplified CFR dataset (not shown 453 for brevity).

$454 \quad$ More significant is the effect of data reduction on mean maximum load effect, $\bar{L}_{\max }$ (Eq. 455 2). The ratio of $\bar{L}_{\text {max }}$ for a reduced dataset to the exact case using all data $\left(\bar{L}_{\max r} / \bar{L}_{\max e}\right)$ for the 
MI-LEP and Simplified CFR databases for moment and shear are given in Figure 6. As shown in

457 the figure, for all cases, reducing the data set results in an over-estimation of $\bar{L}_{\text {max }}$. This is not 458 surprising, as the reduced database becomes more severely biased towards heavier vehicles as it is 459 reduced. In general, the degree of over-estimation increases as span length increases. As shown in 460 the figure, for both databases and load effects, depending on span length, the $\bar{L}_{\max r} / \bar{L}_{\max e}$ ratio 461 ranged from $1.0-1.02$ when reducing the data to $50 \% ; 1.0-1.04$ when reduced to $20 \% ; 1.0-1.06$ 462 when reduced to $10 \%$ and $5 \%$; and $1.0-1.07$ when reduced to $1 \%$. Thus, when using only $1 / 100^{\text {th }}$ 463 of the original database, at most, a 7\% overestimation of mean maximum load effect was found.

\section{Effect of Data Reduction on Required Load Effect and Girder Reliability}

Of primary concern is how using a GVW-reduced database will affect the ultimate product

466 of interest, the required live load effect (RLE) to be used for rating; i.e. the quantity $\gamma_{L L}(L L+I M)$

467 in Eq. 9, and the corresponding computed reliability levels of the bridge girders. Using the revised 468 live load random variable statistical parameters discussed above, RLE values were recomputed for 469 the reduced data set cases. Ratios of the RLE for the reduced data to the exact (i.e. all data) case, $470\left(R_{L} / E_{r} / R E_{e}\right)$, are given in Table 3. Note that if the vehicle model itself is left unchanged, as is 471 typical, the $\left(\mathrm{RLE}_{\mathrm{r}} / \mathrm{RLE}_{\mathrm{e}}\right)$ ratio represents the fractional increase in the live load factor $\left(\gamma_{L L}\right)$. As 472 seen in the table, the $\left(\mathrm{RLE}_{\mathrm{r}} / \mathrm{RLE}_{\mathrm{e}}\right)$ ratios are all greater than unity. This implies that the RLE 473 values, or practically, the live load factors $\gamma_{L L}$ calculated using the reduced data sets produce 474 conservative results. Given that both live load random variable statistics $V_{\max L}$ and $\bar{L}_{\max }$ increase 475 for the reduced data sets, this result is inevitable. This is because increasing either parameter results 476 in an under-estimation of the true reliability index, requiring an increase in live load factor $\gamma_{L L}$ to 477 restore reliability index to the minimum acceptable level. 
Table 3 provides values for the minimum, maximum, and mean ratios from the 195 bridge

479 girder cases described earlier. As shown in Table 3, the average $\mathrm{RLE}_{\mathrm{r}} / \mathrm{RLE}_{\mathrm{e}}$ ratio of all cases

480 using datasets reduced to $10 \%$ varies from $1.02-1.07$. Note that in some cases, the maximum

481 ratio found from any of the cases is quite high; for example, again considering the $10 \%$ dataset,

482 the Simplified CFR vehicles produces a maximum ratio of 1.19 (this occurs for the case of a $18 \mathrm{~m}$

483 reinforced concrete girder (3.6 m spacing); other high ratio cases that approach this value are a 54

$484 \mathrm{~m}$ prestress concrete I-girder (1.2 m spacing) as well as spread box beam spans greater than $30 \mathrm{~m}$.

485 Although few in number and conservative, these outlying cases appear to be significantly 486 discrepancies, perhaps unacceptable. Due to how rating models are typically implemented in 487 common practice, however, using load factors rather than girder-specific RLE values, the actual 488 deviation from using the exact dataset is actually much smaller. This issue is discussed in further 489 detail below.

490 The resulting minimum, maximum, and mean rating reliability indices of the girders are 491 given in Table 4. These are computed using the RLE $\mathrm{r}_{\mathrm{r}}$ values found from the GWV-reduced data 492 pools to rate the girders, then assessing reliability using the exact live load statistics found from 493 all of the data. Thus, the values in Table 4 indicate actual resulting rating reliability indices if the 494 GVW-reduced data were used to develop the load model. As shown, as the data used to construct 495 the live load random variable is reduced, results become more conservative and the actual 496 reliability index increases. Also shown on the table is the resulting reliability index if the suggested 497 AASHTO approach (Eq. 1) is used. That is, girders are rated by calculating the mean and standard 498 deviation of the top $20 \%$ of GVWs and then the load factor $\left(\gamma_{L L}\right)$ found from Eq. 1 is applied to 499 develop the RLE $\left(\gamma_{L L}(L L+I M)\right)$. As shown, results are extremely conservative, in most cases 500 greatly exceeding the minimum required reliability target of 1.5. Here the "mean" results in Table 
4 may appear problematic, as the MBE specifies a minimum reliability target of 1.5 for any case, but that the average of all cases should be no lower than 2.5. For the best comparison of the effect of the reduced data sets, this average limit was not imposed in the solutions presented in Tables 3 or 4 (imposing the higher average limit would obscure the differences in results between the sets). A more practical comparison based on how rating models are commonly implemented is given in the section below, in which both the minimum and average MBE criteria are met.

\section{Effect of Data Reduction on Load Factors}

The previous comparisons shown in Tables 3 and 4 were based on theoretically ideal, girder-specific RLE values. That is, the effect of using the reduced database was compared to an exact case where different RLE values were specifically computed for each individual girder. In practice, this ideal result would amount to using a different load model or load factor that was developed specifically for each bridge girder. Although useful for theoretical assessment, in practice, this approach, and the corresponding resulting discrepancies, is unrealistic. Thus, rather than using ideal RLE values that are girder-specific, as in the previous comparisons, here the effect of reduced data sets on generalized rating live load factors is considered. In a typical DOT rating model, similar to design, a constant live load factor $\gamma_{L L}$ is used to rate all girders in the bridge inventory. To determine the appropriate inventory-wide rating live load factor, first girder-specific live load factors are determined. These are found by calculating the rating vehicle load effect $(L L)$ specific to each hypothetical girder considered, then determining the needed live load factor $\gamma_{L L}$ to be used such that the RLE $\left(\gamma_{L L}(L L+I M)\right)$ is met such that no girder has a reliability index less than 1.5, and the average reliability index of all cases considered is no less than 2.5. The maximum of all girder-specific $\gamma_{L L}$ values needed for any girder to meet $\beta \geq 1.5$ is then chosen to be used with the rating vehicle(s) for all girders, provided that the required average $\beta_{\text {ave }} \geq 2.5$ is met. 

rating for all types of girders except the single governing case. Minimizing this conservatism can

526 be accomplished by refining the rating vehicle model $(L L)$ to better match the RLEs, a topic which

527 has been addressed elsewhere (see Siavashi and Eamon 2019, for example). However, to examine 528 results using the reduced datasets, the above procedure is followed to determine the required live 529 load factor $\left(\gamma_{L L}\right)$. In this analysis, existing rating vehicles are used for the live load effect $(L L)$, 530 which are taken to be those currently used by MDOT (Curtis and Till 2008, MDOT 2009) for the 531 MI-LEP database and the AASHTO rating vehicles described in the MBE for the Simplified CFR 532 database. These results are given in Figure 7. Note that the figure provides different required load 533 factors for moment and shear, but the single governing factor for either would be used in practice. 534 Also shown in the figure are the load factors found from using the suggested AASHTO procedure 535 (Eq. 1). As expected based on previous results, it was found that a higher load factor resulted as 536 the datasets were reduced. Reducing the dataset to $10 \%$ of the heaviest vehicles resulted in a ratio 537 of reduced to exact live load factors $\left(\gamma_{L L r} / \gamma_{L L e}\right)$ of 1.05 and 1.04 for moment and 1.04 and 1.03 538 for shear for the MI-LEP and Simplified CFR databases, respectively. Only using $1 \%$ of the 539 heaviest vehicles in the database resulted in $\left(\gamma_{L L r} / \gamma_{L L e}\right)$ ratios of 1.10 and 1.06 for moment and 5401.06 and 1.05 for shear for the two respective databases. In contrast, the AASHTO procedure 541 produced load factor ratios of 2.67 and 1.36 for moment and 2.06 and 1.03 for shear for the two 542 databases. It should be again noted that the load factors shown in Fig.7 include results only from 543 the single-lane load effects, and thus represent worst-case discrepancies using the reduced data 544 sets. That is, because some of the bridge geometries considered are governed by two lane load 545 effects, and the proposed reduction method does not affect two lane results, the final load factor, 546 taken as the maximum of either the single lane or two-lane load effect, may in fact be completely 
547

548

549

550

551

552

553

554

555

556

557

558

559

560

561

562

563

564

565

566

567

568

569

unaffected. Whether this may occur or not is database dependent. For example, considering the MI-LEP database, approximately $58 \%$ of the girder cases for moment and $13 \%$ of the cases for shear were dominated by two-lane effects. From these results, it was found that the two-lane $6 \mathrm{~m}$ side-by-side spread box ( $0.9 \mathrm{~m}$ width) load factor governed overall for shear and the one-lane $6 \mathrm{~m}$ side-by-side spread box ( $0.9 \mathrm{~m}$ width) governed for moment, resulting in maximum load factors of 1.07 for shear and 1.11 for moment, respectively. Also note that, although moment and shear load factors are separated for illustration in the figure, the single governing load factor for moment or shear would be used in practice (and thus in this case, the single-lane effect dominated overall). The reliability indices associated with the use of the inventory-wide load factors given in Figure 7 are shown in Table 5. Notice in the table, that even using the exact procedure that considers all data, a large variation in reliability among the different girder cases exists. A large variation is not atypical (Nowak 1999, Kamjoo and Eamon 2018), and is due to an inadequacy of the existing rating live load model, via the load effects caused by the idealized rating trucks used ( $L L)$, to capture the actual load effects. Again considering the exact result using all data, note that either the minimum reliability index (for MI-LEP Moment and Shear, and for Simplified CFR Shear), or the average reliability index (for Simplified CFR Moment) will govern the load factor required. Which will govern is case dependent and depends on both the database and rating trucks used. Also notice as the size of the database is decreased, both the minimum and mean reliability index increase, due to the increased level of conservatism that results. Similar to the results of Figure 7 , in general, only modest increases in conservatism result for rather large reductions in the database size. For example, reducing the database by an order of magnitude (i.e. to the Top 10\%) causes an average increase in girder reliability index from 3.63 to 3.77 for moment and from 3.40 to 3.50 for shear considering the MI-LEP case, and from 2.50 to 2.60 for moment and 2.72 to 2.78 for shear 
570 considering the Simplified CFR case. However, much larger discrepancies in reliability are found

571 from the AASHTO procedure, as shown in the table.

572 In fairness, although there are no specific limitations given to the use of Eq. 1, a suggested 573 scenario for use of this expression given in the code commentary is to develop live load factors for 574 a localized, low-volume road carrying heavy trucks. Therefore, to see if Eq. 1 might provide better 575 results in this situation, rather than combine all traffic data to produce state-wide load factors, as 576 done for all previous results presented, the analyses above were repeated individually for 14 577 different WIM sites, with varying ADTT from 360-16,500. These results are shown in Figures 8 578 and 9 for both the MI-LEP and Simplified CFR databases, respectively (note in these site-specific 579 analyses, $V_{\text {site }}$ in Eq. 6 is set to zero). Although Eq. 1 suggests a minimum load factor of 1.80; this 580 minimum is not directly imposed in the result of Eq. 1 in the figures, which would result in greater 581 discrepancies. As shown in the figures, using site-specific data rather than state-wide data has little 582 impact on the effectiveness of using the GVW-reduced dataset as proposed, as well as the larger 583 discrepancy generally found from the AASHTO Method. to exact load factor ratio $\left(\gamma_{L L} / \gamma_{L L}\right)$ varies from 1.02 to 1.11 considering the top $10 \%$ of data, 586 with an average of 1.06 (reduced to ratios from1.01 to 1.06 with an average of 1.03 if the top $20 \%$ 587 is considered), while the AASHTO simplified procedure produced ratios from 1.18 to 1.50 with 588 an average of 1.34. Considering shear, the WIM site-specific $\left(\gamma_{L L r} / \gamma_{L L}\right)$ ratios varied from 1.01 589 to 1.09 considering the top $10 \%$, with an average of 1.05 (reduced to ratios from 1.00 to 1.04 with 590 an average of 1.02 considering the top 20\%), while the AASHTO resulted in ratios from 1.02 to $591 \quad 1.33$ with an average of 1.23 . 
For the MI-LEP database, the effectiveness of the proposed procedure remains similar,

while the results of the AASHTO method significantly worsened. Considering the Simplified CFR moment, assessing all 14 sites individually, the reduced to exact load factor ratio $\left(\gamma_{L L r} / \gamma_{L L e}\right)$ varies from 1.04 to 1.10 considering the top $10 \%$ of data, with an average of 1.07 (reduced to ratios from 1.01 to 1.07 with an average of 1.04 if the top $20 \%$ is considered), while the AASHTO simplified procedure produced ratios from 1.60 to 3.06 with an average of 2.50. Considering shear, the WIM site-specific $\left(\gamma_{L L r} / \gamma_{L L e}\right)$ ratios varied from 1.03 to 1.11 considering the top $10 \%$, with an average of 1.07 (reduced to ratios from 1.02 to 1.06 with an average of 1.04 considering the top 20\%), while the AASHTO resulted in ratios from 1.72 to 3.24 with an average of 2.66 .

Although the results given in Tables 3-5 concern Strength I vehicles associated with rating, a common concern for state DOTs, the method was also evaluated on a vehicle pool unfiltered with regard to GVW, that would perhaps represent a combined Strength I/Strength II calibration for design (Eamon et al. 2016) containing the very heaviest vehicles, with an associated target reliability level of 3.5 (Nowak 1999). It was found that the proposed method was equally effective in this case, where ratios of $\mathrm{RLE}_{\mathrm{r}} / \mathrm{RLE}_{\mathrm{e}}$ (i.e. values shown in Table 3 ) as well as differences in reliability index (i.e. Tables 4 and 5) were no greater than those presented for rating.

Although only simple span results are presented, 2-span continuous bridges otherwise identical to the simple span cases were also investigated for the MI-LEP database. In general, it was found that GVW is equally well correlated to continuous span shear and moment load effects. It was also found that differences in reliability when using the reduced datasets and the exact case (i.e. all data) were very similar to those found with the simple spans. A few exceptions were: shears at the top $1 \%$ data reduction case for girder-specific load factors (per Table 4) were more conservative than for the simple spans; and for the single governing load factor analysis (per Table 
615 5) for the top 5\% case, continuous moments provided less discrepancy but continuous shears more discrepancy as compared to the simple span cases, while for the top $1 \%$ case, continuous moments

617 provided more discrepancy and continuous shears less discrepancy than for simple spans.

\section{Conclusion}

In this study, the effects of using a GVW-based load truncation approach to develop Statespecific live load factors for rating was evaluated. Two different traffic datasets representative of

621 unusually heavy as well as typically legal vehicles were considered. A strong correlation was found

622 between GVW and load effects, with correlation coefficient varying from about 0.9 to nearly 1.0

623 for both vehicle databases. Reducing the datasets to as little as $1 \%$ of the top GVW data generally

624 resulted in insignificant increases in COV of mean maximum load effect, whereas reducing the 625 data to as much as the top $10 \%$ resulted in an increase in mean maximum load effect from 1-6\%, 626 depending on span length. Reducing the data to the top 5\% increased idealized (i.e. girder-specific) 627 average required load factors to $4-5 \%$ considering the MI-LEP database and up to $8 \%$ for the 628 Simplified CFR, with associated increases in mean minimum reliability index from 1.5 to 629 approximately 1.6. This is in comparison to the suggested simplified AASHTO procedure, which 630 produced mean minimum indices of about 3-5.

If used as commonly implemented in DOT rating practice, when the same rating live load 632 factor(s) is used for all girders in the bridge inventory, reducing the dataset to the top $10 \%$ 633 increased live load factors from 3-5\%, while only using $1 \%$ of the heaviest vehicles approximately 634 doubled these discrepancies. In contrast, the simplified AASHTO procedure increased load factors 635 by factors of 1.36 and 2.67 for moment and 1.03 and 2.06 for shear, depending on the database 636 considered. Similar results were obtained for WIM site-specific rather than statewide consideration 637 of traffic data. In all cases, use of the reduced databases produced conservative results. 
It thus appears that the use of the load truncation approach to develop State-specific live

639

640

641

642

643 644 factor.

645

646

647

648

649

650

651

652

653

654

655

656

657

658

659

660

661

662

663 load rating factors appears highly promising, where large reductions in computational effort can

be achieved with minimal loss of accuracy. Although what amount of computational effort and error are acceptable must be determined by the analyst, using approximately the top $10 \%$ by GWV appears to be a reasonable starting point, where an order of magnitude of reduced computational effort consistently produced less than a 5\% (conservative) discrepancy in inventory-wide load

\section{Data Availability Statement}

Some or all data, models, or code used during the study were provided by a third party (weigh-in-motion data). Direct requests for these materials may be made to the provider as indicated in the Acknowledgements.

\section{Acknowledgments}

The weigh-in-motion data used in this study was provided by the Michigan Department of Transportation, whose support is greatly acknowledged.

\section{REFERENCES}

AASHTO. 1994. Manual for condition evaluation of bridges, (including 1998 interim revision). Washington, DC: AASHTO.

AASHTO. 2003. Manual for condition evaluation and load and resistance factor rating (LRFR) of highway bridges. Washington, DC: AASHTO.

AASHTO. 2017. LRFD Bridge Design Specifications, 8th Ed., Washington, DC: AASHTO. 
AASHTO. 2018. Manual for bridge evaluation, 3rd Ed., Washington, DC: AASHTO.

Acar, E., Rais-Rohani, M., and Eamon, C. 2010. "Reliability Estimation Using Univariate Dimension Reduction and Extended Generalized Lambda Distribution.” International Journal of Reliability and Safety, Vol. 4, No. 2/3, pp. 166-187.

Anitori, G., Casas, J.R., and Ghosn, M. 2017. "WIM-based live-load model for advanced analysis of simply supported short- and medium-span highway bridges." J. Bridge Eng. 22 (10): 04017062. https://doi.org/10.1061/(ASCE)BE.1943-5592.0001081.

Curtis, R., and R. Till. 2008. Recommendations for Michigan specific load and resistance factor design loads and load and resistance factor rating procedures. MDOT Research Rep. R1511. Lansing, MI: Michigan Dept. of Transportation.

Eamon, C. D., Kamjoo, V., and Shinki, K. 2014. Side by side probability for bridge design and analysis. MDOT Report RC-1601. Lansing, MI: Michigan Dept. of Transportation.

Eamon, C., V. Kamjoo, and K. Shinki. 2016. "Design live-load factor calibration for Michigan highway bridges.” J. Bridge Eng. 21 (6) :04016014. https://doi.org/10.1061/(ASCE)BE.1943 5592.0000897.

Eamon, C. D., and Siavashi, S. 2018. Developing Representative Michigan Truck Configurations for Bridge Load Rating. Rep. No. SPR-1640. Lansing, MI: Michigan. Dept. of Transportation.

Fu, G., Hag-Elsafi, O. 2000. "Vehicular overloads: Load model, bridge safety, and permit checking" J. Bridge Eng., 5(1), 49-57. https://doi.org/10.1061/(ASCE)10840702(2000)5:1(49).

Fu, G., Chi, J. and Wang, Q., 2019. Illinois-Specific LRFR Live-Load Factors Based on Truck Data. Illinois Center for Transportation/Illinois Department of Transportation. 
687 Ghosn M, Sivakumar B, and Miao F. 2011. Load and resistance factor rating (LRFR) in NYS,

688

689

690

691

692

693

694

695

696

697

698

699

700

701

702

703

704

705

706

707

Final Report. NYSDOT Report C-06-13, New York State Department of Transportation.

Kamjoo, V. and Eamon, C. 2018. "Reliability-Based Design Optimization of a Vehicular Live Load Model.” Engineering Structures, no. 168: 799-808.

Kwon, O. S., Orton, S., Salim, H., Kim, E. and Hazlett, T. 2010. Calibration of the live load factor in LRFD design guidelines. MODOT Rep. ORI1-003. Jefferson City, MO: Missouri Dept. of Transportation.

Lee, C. E., and Souny-Slitine, N. 1998. Final research findings on traffic-load forecasting using weigh-in-motion data. Rep. 987-7. Austin, TX: Center for Transportation Research Bureau of Engineering Research, Univ. of Texas at Austin.

MDOT (Michigan Dept. of Transportation). 2005. Bridge analysis guide with 2009 interim update, parts 1 and 2. Lansing, MI: Michigan Dept. of Transportation Construction and Technology Support Area.

Miao, T.J. and Chan. T.H.T. 2002. Bridge live load models from WIM data. Engineering Structures, Vol. 24, No. 8, pp. 1071-1084. 2002.

Moses, F. 2001. Calibration of load factors for LRFR bridge evaluation. NCHRP Report 454. Washington, DC: Transportation Research Board.

Nowak AS. 1999. Calibration of LRFD bridge design code." NCHRP Report 368. Washington, DC: Transportation Research Board.

Nowak, A. S., and Rakoczy, P. 2013. WIM-based live load for bridges. KSCE Journal of Civil Engineering, 17(3), 568-574. 
O'Brien, E.J. Enright, B., and Getacllew, A. 2010. Importance of the Tail in Truck Weight Modeling for Bridge Assessment. J Bridge Eng., Vol. 15, No.2, pp. 210-213. https://doi.org/10.1061/(ASCE)BE.1943-5592.0000043.

O'Brien EJ, Enright B. 2012. Using weigh-in-motion data to determine aggressiveness of traffic for bridge loading.” J Bridge Eng., 18(3):232-9 https://doi.org/10.1061/(ASCE)BE.19435592.0000368.

Pelphrey J, Higgins C. 2006. Calibration of LRFR live load factors using weigh-in-motion data. ODOT Report SPR 635. Oregon: Oregon Dept. of Transportation.

Siavashi, S., and Eamon, C. D. 2019. Development of Traffic Live-Load Models for Bridge Superstructure Rating with RBDO and Best Selection Approach. J Bridge Eng., 24(8), 04019084. https://doi.org/10.1061/(ASCE)BE.1943-5592.0001457.

Sivakumar, B., Ghosn, M., and Moses, F. 2011. Protocols for collecting and using traffic data in bridge design NCHRP Report 683. Washington, DC: Transportation Research Board.

Sivakumar, B., and Ghosn, M. 2011. Recalibration of LRFR live load factors in the AASHTO manual for bridge evaluation NCHRP Project, (20-07). Washington, DC: Transportation Research Board.

Tabatabai H, Zhao J, Lee C-W. 2009. Statistical analysis of heavy truck loads using Wisconsin weigh-in-motion data. WDOT Project CFIRE 01-02. WI: Wisconsin Department of Transportation.

U.S. Department of Transportation, Federal Highway Administration. 1994. Federal size regulations for commercial motor vehicles. Code of Federal Regulations (CFR); 23 CFR Part 658. 
747 Table 1. Vehicle Filtering Criteria.

\begin{tabular}{ll}
\hline Vehicle Type & Criteria \\
\hline Legal, & For axles spaced $\geq 2.75 \mathrm{~m}$, axles $\leq 80 \mathrm{kN}$ \\
GVW $>356 \mathrm{kN}$ & For axles spaced from $1-2.7 \mathrm{~m}$, axles $\leq 58 \mathrm{kN}$ \\
& For axles spaced $<1 \mathrm{~m}$, axles $\leq 40 \mathrm{kN}$ \\
& $2 \leq$ Number of axles $\leq 11$ \\
& Vehicle Length $\leq 29 \mathrm{~m}$ \\
\hline Legal, & Any individual axle $\leq 89 \mathrm{kN}$ \\
& Sum of tandem axles $\leq 151 \mathrm{kN}$ \\
GVW $<356 \mathrm{kN}$ & $2 \leq$ Number of axles $\leq 11$ \\
& Vehicle Length $\leq 29 \mathrm{~m}$ \\
\hline
\end{tabular}




\begin{tabular}{lll}
\cline { 2 - 2 } $\begin{array}{l}\text { MI-Legal and } \\
\text { Extended Permit } \\
\text { (MI-LEP) }\end{array}$ & $\begin{array}{l}\text { Permit } \\
\text { (Construction)* }^{*}\end{array}$ & $\begin{array}{l}\text { Any axle } \leq 107 \mathrm{kN} \\
\mathrm{GVW} \leq 667 \mathrm{kN} \\
2 \leq \text { Number of axles } \leq 11 \\
\text { Vehicle Length } \leq 26 \mathrm{~m}\end{array}$ \\
\hline & & GVW $\leq 356 \mathrm{kN}$ \\
Simplified CFR & Any axle $\leq 89 \mathrm{kN}$ \\
& For axles spaced from $1-2.4 \mathrm{~m}$, Sum of tandem axles $\leq 151 \mathrm{kN}$
\end{tabular}

$748 *$ Various types of permits exist, depending on vehicle use category and cargo type. Permits for construction vehicles 749 are generally most permissive and govern load effects. 
Table 2. Random Variables.

\begin{tabular}{llll}
\hline Random Variable & \multicolumn{2}{l}{ Bias Factor } & COV \\
\hline Resistance RVs & $R$ & & \\
\hline Prestressed Concrete, Moment & & 1.05 & 0.075 \\
Prestressed Concrete, Shear & & 1.15 & 0.14 \\
Reinforced Concrete, Moment & 1.14 & 0.13 \\
Reinforced Concrete, Shear ${ }^{1}$ & & 1.20 & 0.155 \\
Steel, Moment & 1.12 & 0.10 \\
Steel, Shear & 1.14 & 0.105 \\
\hline Load RVs & & & \\
\hline Vehicle Live Load, Moment & $L_{\max }$ & $1.14-1.73^{2}$ & $0.14-0.21^{3}$ \\
Vehicle Live Load, Shear & $L_{\max }$ & $1.14-1.64^{2}$ & $0.15-0.19^{3}$ \\
Vehicle Dynamic Load & $I_{M}$ & $1.13^{4}$ & 0.09 \\
Vehicle Load Distribution Factor & $D F$ & $0.72-0.79$ & $0.11-0.16$ \\
Dead Load, Prefabricated & $D_{p}$ & 1.03 & 0.08 \\
Dead Load, Site-Cast & $D_{s}$ & 1.05 & 0.10 \\
Dead Load, Wearing Surface & $D_{w}$ & mean $89 \mathrm{~mm}$ & 0.25 \\
\hline
\end{tabular}

1. Assumes shear stirrups present.

2. Bias factor is given for the MI-LEP data as the ratio of mean load effect to the governing nominal Michigan legal rating truck load effect. For the Simplified CFR data, bias factor is 1.50-1.95 for moment and 1.59-1.90 for shear, and is given as the ratio of mean load effect to the governing nominal AASHTO legal rating truck load effect.

756 3. Includes uncertainties from data projection, site, WIM data, impact factor, and load distribution. 
779 Table 3. Required Load Effect Ratios.

\begin{tabular}{llllll}
\hline Reduced & \multicolumn{3}{c}{ MI-LEP } & \multicolumn{2}{c}{ Simplified CFR } \\
\cline { 2 - 6 } Dataset & RLE $_{\mathrm{r}}$ RLE & Moment & Shear & Moment & Shear \\
\hline \multirow{2}{*}{ Top 50\% } & maximum & 1.04 & 1.04 & 1.07 & 1.09 \\
& mean & 1.01 & 1.01 & 1.03 & 1.02 \\
& minimum & 1.00 & 1.00 & 1.00 & 1.00 \\
\hline \multirow{2}{*}{ Top 20\% } & maximum & 1.07 & 1.07 & 1.16 & 1.14 \\
& mean & 1.03 & 1.03 & 1.06 & 1.04 \\
& minimum & 1.02 & 1.01 & 1.00 & 1.01 \\
\hline \multirow{3}{*}{ Top 10\% } & maximum & 1.08 & 1.08 & 1.19 & 1.18 \\
& mean & 1.05 & 1.03 & 1.07 & 1.06 \\
& minimum & 1.03 & 1.01 & 1.01 & 1.02 \\
\hline \multirow{2}{*}{ Top 5\% } & maximum & 1.09 & 1.10 & 1.21 & 1.23 \\
& mean & 1.05 & 1.04 & 1.08 & 1.08 \\
& minimum & 1.04 & 1.01 & 1.01 & 1.03 \\
\hline \multirow{2}{*}{ Top 1\% } & maximum & 1.10 & 1.13 & 1.27 & 1.26 \\
& mean & 1.06 & 1.05 & 1.10 & 1.10 \\
& minimum & 1.04 & 1.01 & 1.01 & 1.03 \\
\hline
\end{tabular}

780

781

782

783

784

785

786

787

788

789

790

791

792

793

794

795

796

797

798 
799 Table 4. Reliability Results for Different Vehicle Database Sizes, Girder-Specific Load Factors.

\begin{tabular}{llllll}
\hline Reduced & Reliability & MI-LEP & \multicolumn{3}{c}{ Simplified CFR } \\
\cline { 3 - 6 } Dataset & Index $(\beta)$ & Moment & Shear & Moment & Shear \\
\hline \multirow{2}{*}{ Top 50\% } & maximum & 1.56 & 1.59 & 1.64 & 1.67 \\
& mean & 1.52 & 1.52 & 1.54 & 1.53 \\
& minimum & 1.51 & 1.50 & 1.51 & 1.50 \\
\hline \multirow{2}{*}{ Top 20\% } & maximum & 1.61 & 1.63 & 1.73 & 1.75 \\
& mean & 1.57 & 1.54 & 1.57 & 1.56 \\
Top 10\% & mean & 1.60 & 1.57 & 1.59 & 1.58 \\
& minimum & 1.53 & 1.51 & 1.51 & 1.52 \\
\hline \multirow{2}{*}{ Top 5\% } & maximum & 1.84 & 1.71 & 1.91 & 1.91 \\
& mean & 1.62 & 1.58 & 1.60 & 1.59 \\
& minimum & 1.53 & 1.52 & 1.52 & 1.53 \\
\hline \multirow{2}{*}{ Top 1\% } & maximum & 1.95 & 1.74 & 2.03 & 1.97 \\
& mean & 1.68 & 1.61 & 1.63 & 1.53 \\
& minimum & 1.54 & 1.54 & 1.52 & 1.61 \\
\hline \multirow{2}{*}{ AASHTO } & maximum & 8.84 & 4.85 & 4.52 & 3.74 \\
& mean & 4.95 & 3.65 & 3.25 & 2.78 \\
\hline & minimum & 6.89 & 2.78 & 2.70 & 1.63 \\
\hline
\end{tabular}

800

801

802

803

804

805

806

807

808

809

810

811

812

813 
814 Table 5. Reliability Results for Different Vehicle Database Sizes, Single Governing Load Factor.

\begin{tabular}{|c|c|c|c|c|c|}
\hline \multirow{2}{*}{$\begin{array}{l}\text { Reduced } \\
\text { Dataset }\end{array}$} & \multirow{2}{*}{$\begin{array}{l}\text { Reliability } \\
\text { Index }(\beta)\end{array}$} & \multicolumn{2}{|c|}{ MI-LEP } & \multicolumn{2}{|c|}{ Simplified CFR } \\
\hline & & Moment & Shear & Moment & Shear \\
\hline \multirow{3}{*}{ All } & maximum & 4.91 & 4.75 & 3.01 & 3.64 \\
\hline & mean & 3.61 & 3.40 & 2.50 & 2.72 \\
\hline & minimum & 1.50 & 1.50 & 1.87 & 1.50 \\
\hline \multirow{3}{*}{ Top 50\% } & maximum & 4.93 & 4.78 & 3.06 & 3.70 \\
\hline & mean & 3.63 & 3.42 & 2.53 & 2.75 \\
\hline & minimum & 1.52 & 1.53 & 1.91 & 1.57 \\
\hline \multirow{3}{*}{ Top 20\% } & maximum & 5.03 & 4.82 & 3.15 & 3.72 \\
\hline & mean & 3.71 & 3.45 & 2.58 & 2.76 \\
\hline & minimum & 1.64 & 1.57 & 1.99 & 1.59 \\
\hline \multirow{3}{*}{ Top $10 \%$} & maximum & 5.09 & 4.88 & 3.20 & 3.74 \\
\hline & mean & 3.77 & 3.50 & 2.60 & 2.78 \\
\hline & minimum & 1.72 & 1.64 & 2.03 & 1.61 \\
\hline \multirow{3}{*}{ Top 5\% } & maximum & 5.19 & 4.91 & 3.24 & 3.76 \\
\hline & mean & 3.85 & 3.52 & 2.62 & 2.79 \\
\hline & minimum & 1.84 & 1.68 & 2.07 & 1.64 \\
\hline \multirow{3}{*}{ Top $1 \%$} & maximum & 5.27 & 4.95 & 3.26 & 3.78 \\
\hline & mean & 3.92 & 3.56 & 2.63 & 2.81 \\
\hline & minimum & 1.94 & 1.73 & 2.10 & 1.66 \\
\hline \multirow{3}{*}{ AASHTO } & maximum & 8.80 & 6.82 & 4.58 & 3.87 \\
\hline & mean & 4.95 & 5.04 & 3.25 & 2.87 \\
\hline & minimum & 6.89 & 3.81 & 2.70 & 1.62 \\
\hline
\end{tabular}

815

816

817 


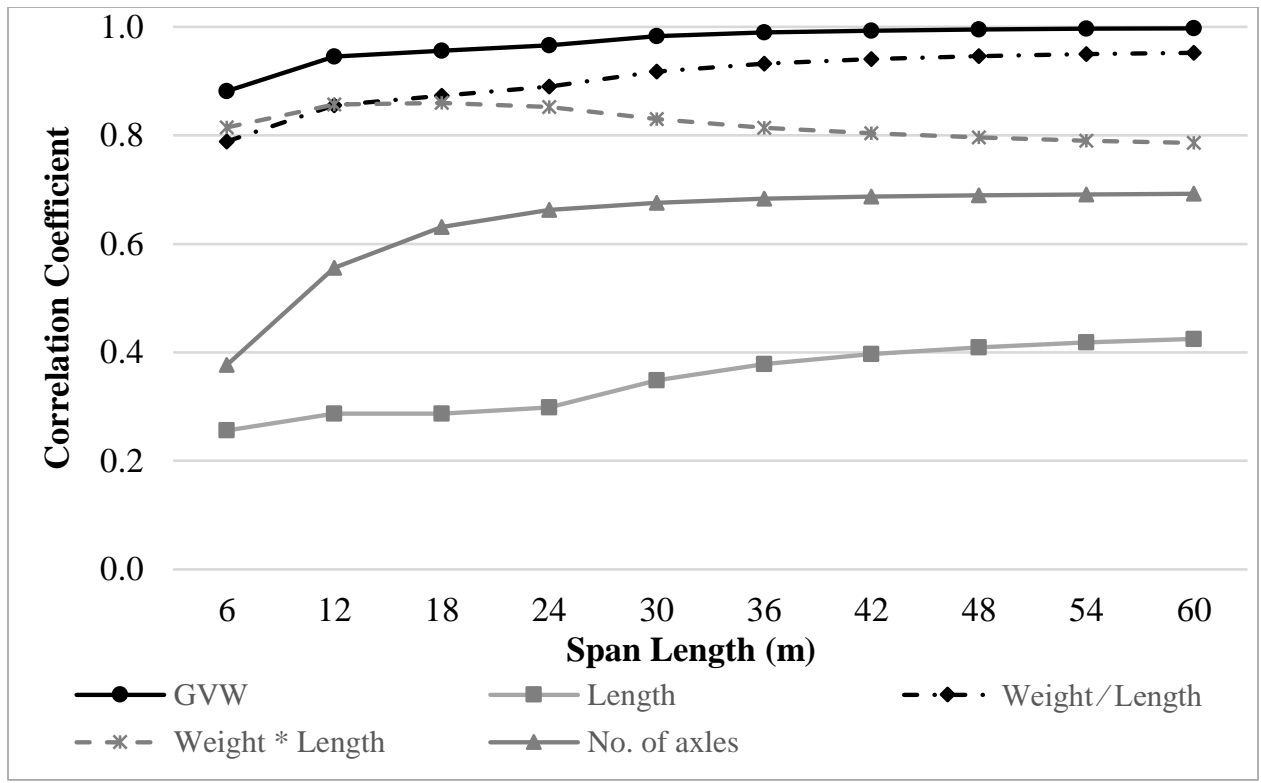

Figure 1. Correlation Between Vehicle Parameter and Moment, MI-LEP. 
841

842

843

844

845

846

847

848

849

850

851

852

853

854

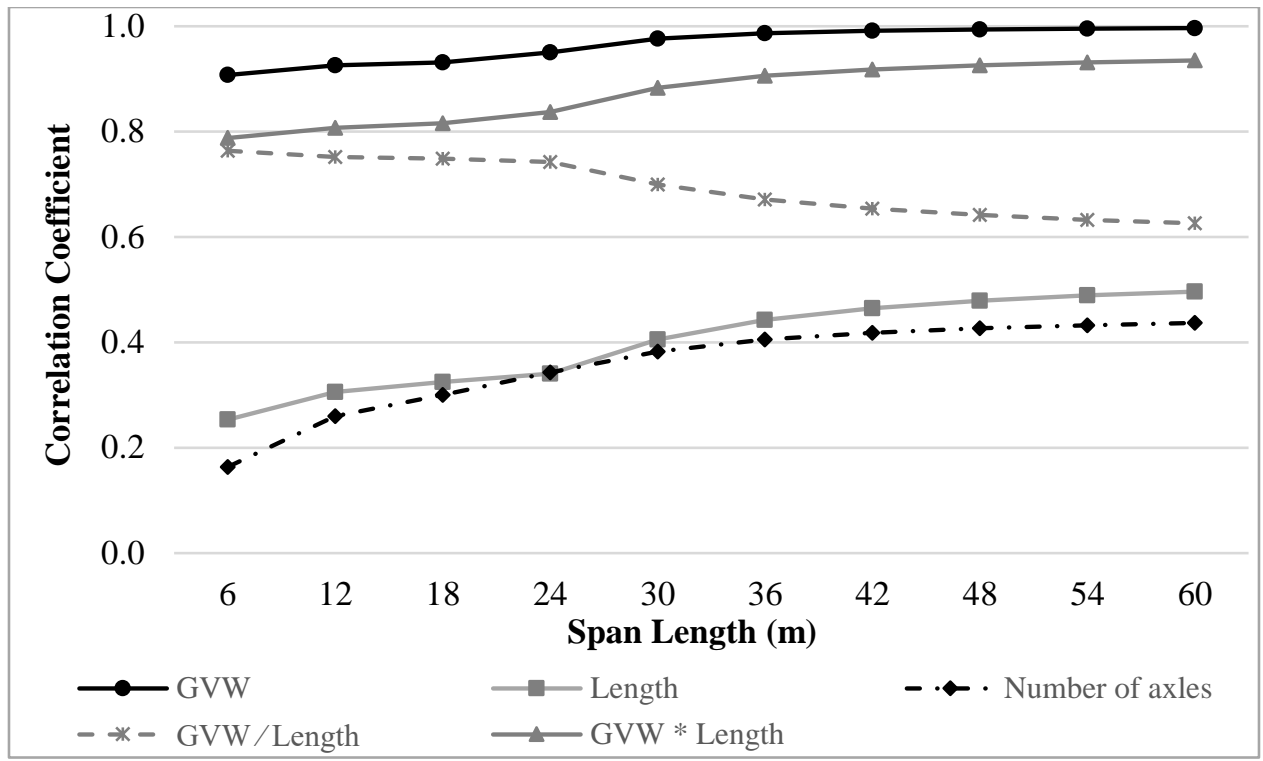

Figure 2. Correlation Between Vehicle Parameter and Moment, Simplified CFR. 


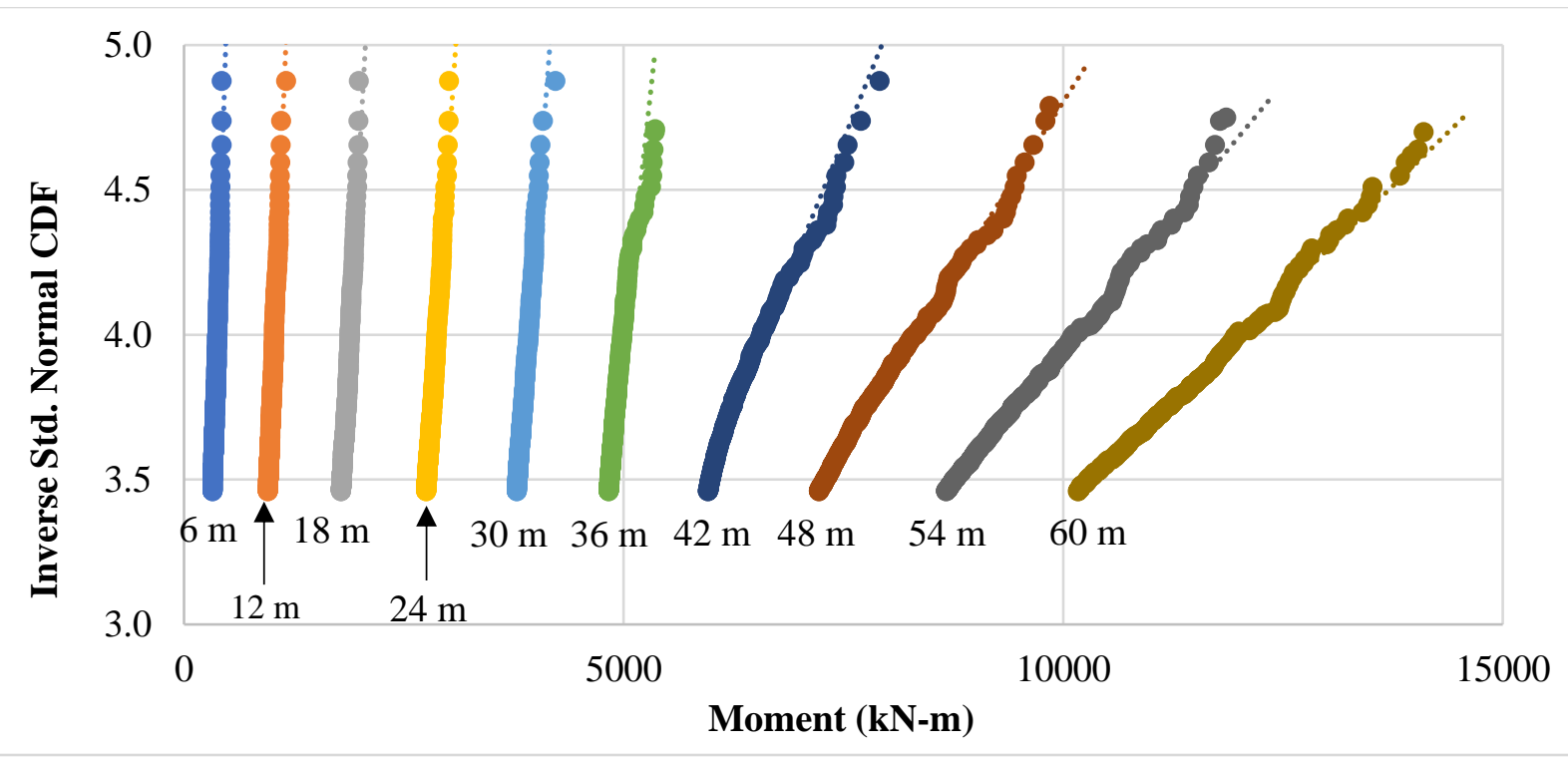

856

Figure 3. Example CDF of 6-60 m Span Moments.

857

858

859

860

861

862

863

864

865

866

867

868

869 


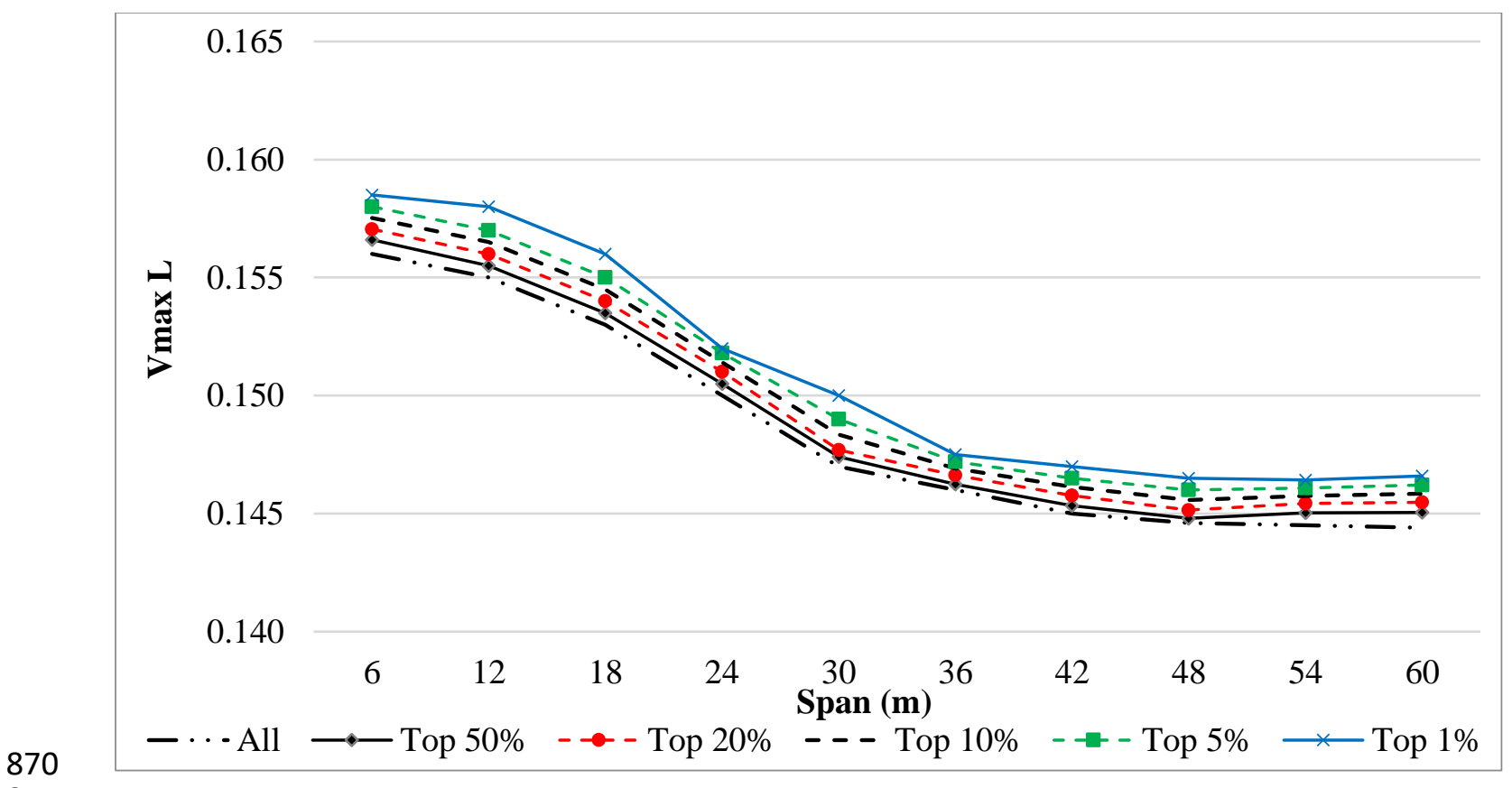

Figure 4. Effect of Database Reduction on $V_{\max L}$ for Moment, MI-LEP Vehicles.

873

874

875

876

877

878

879

880

881

882

883 


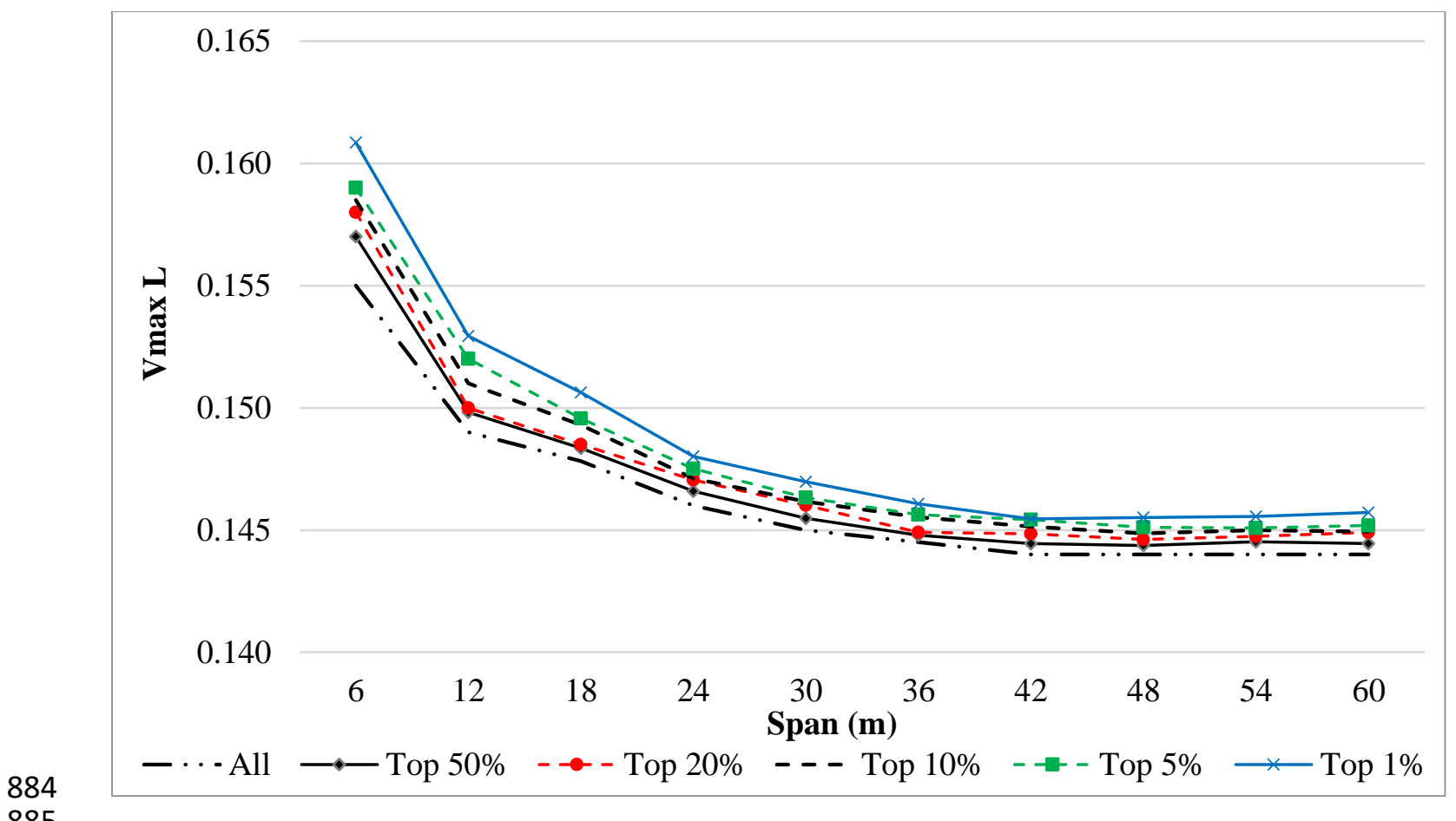

885

886

887

Figure 5. Effect of Database Reduction on $V_{\max }$ for Shear, MI-LEP Vehicles.

888

889

890

891

892

893

894 


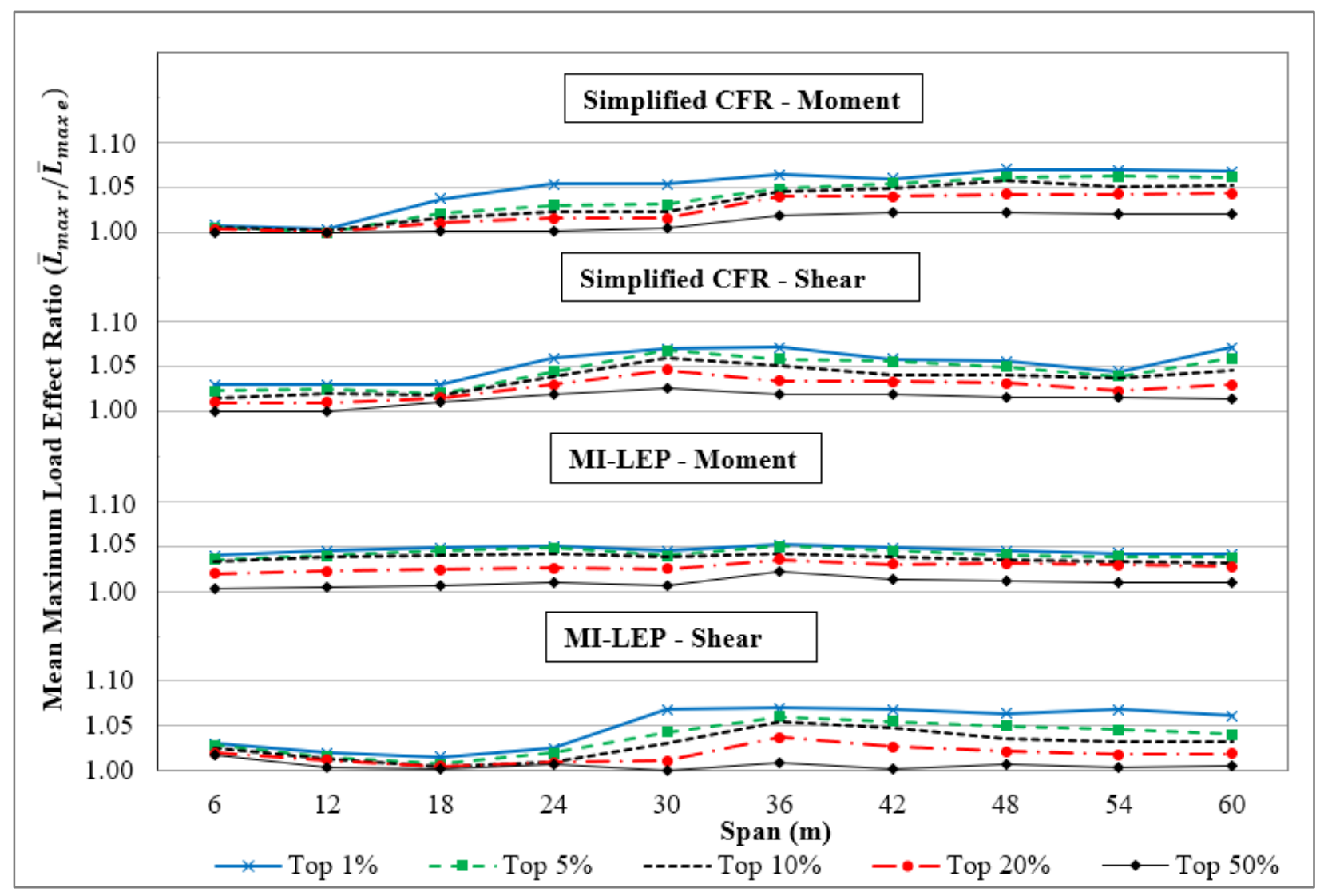

896

897

898

899

900

901

902

903

904

905

906

907

908

909

910

911

912

913

914

915

916

917

Figure 6. Effect of Database Reduction on Mean Maximum Load Effect. 


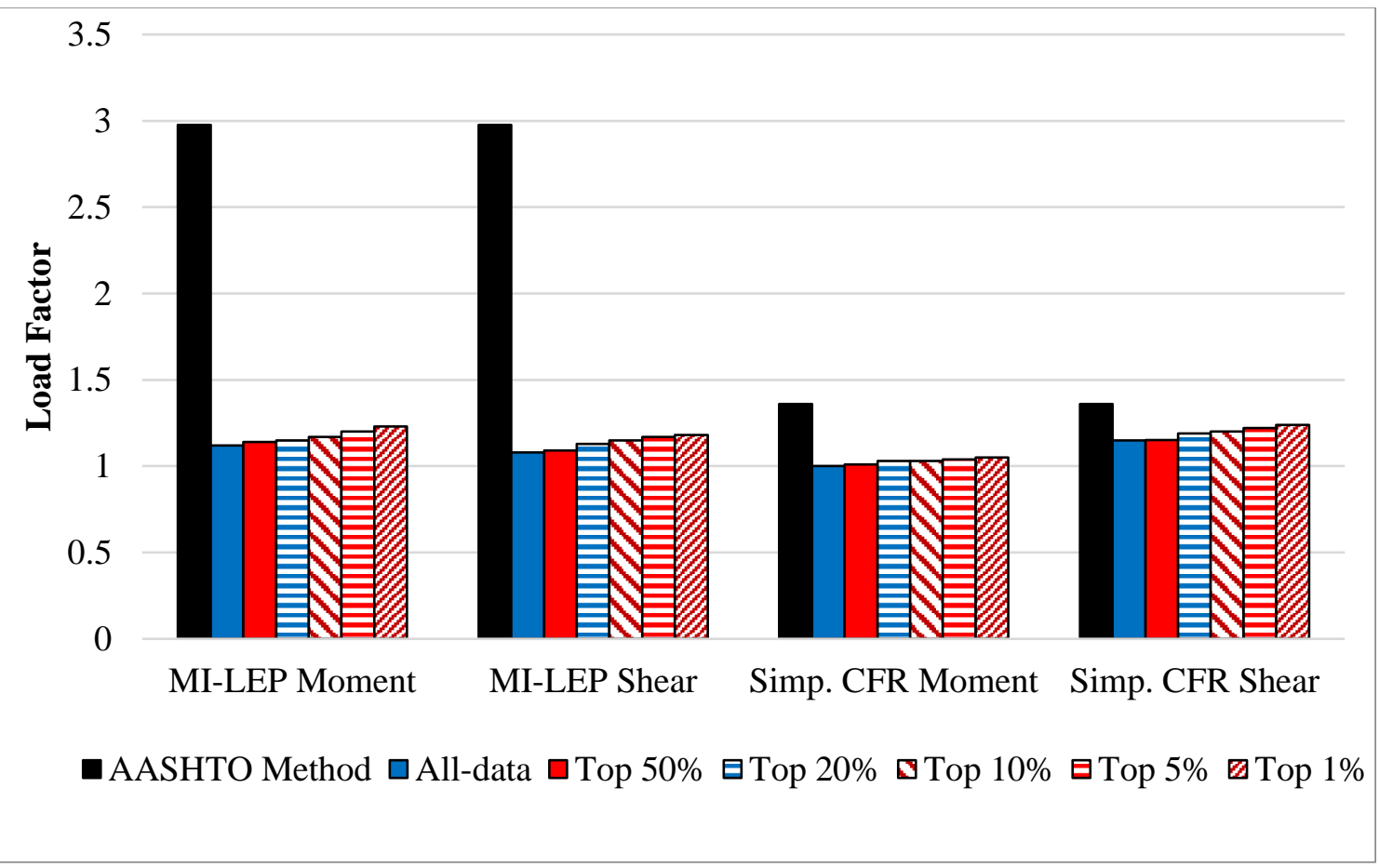

919

Figure 7. Comparison between AASHTO and Proposed Procedure.

920

921

922

923

924

925

926

927

928 


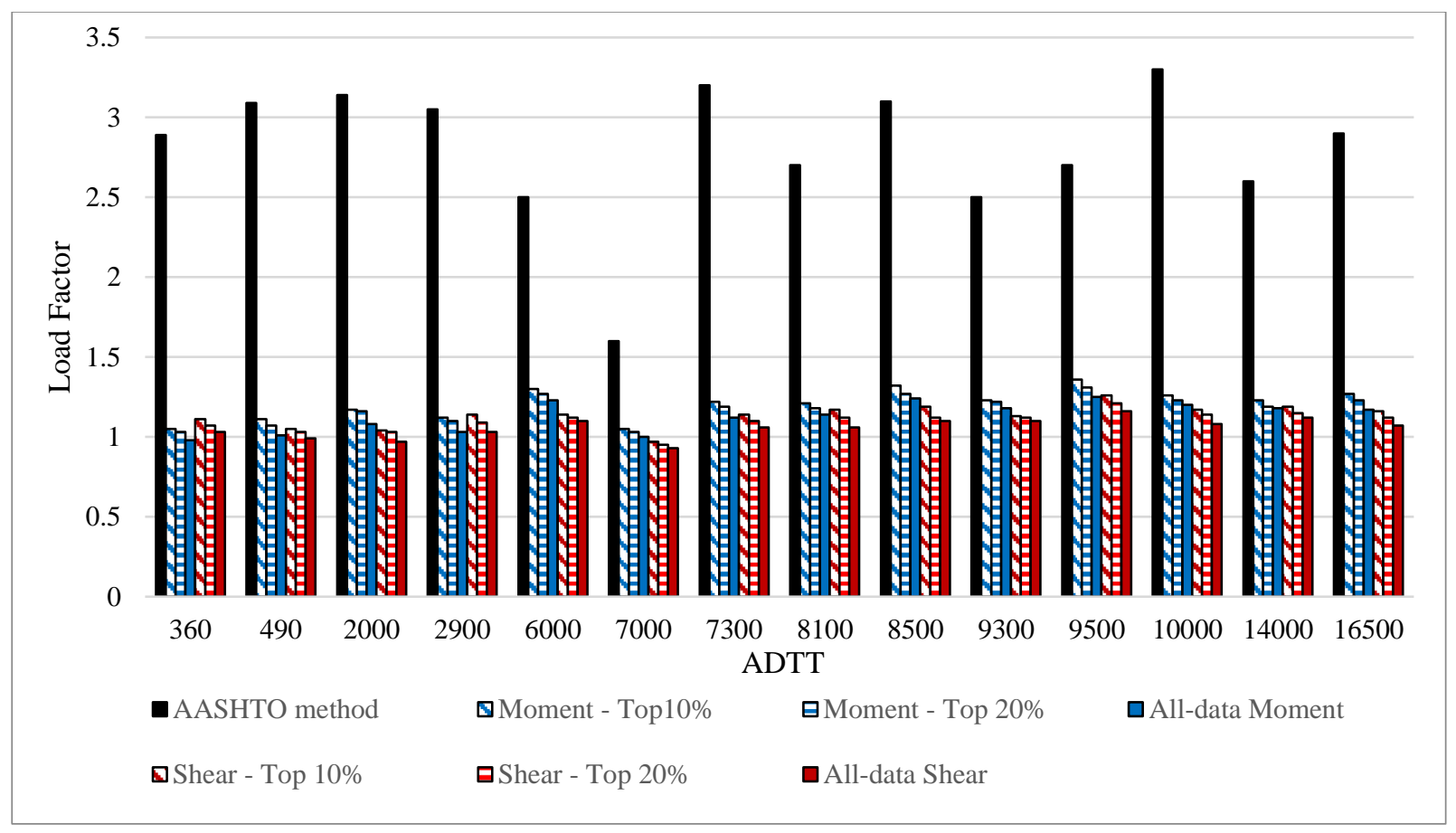

929

931

932

Figure 8. Comparison between AASHTO and Proposed Procedure, MI-LEP.

933

934

935

936

937

938

939

940

941 


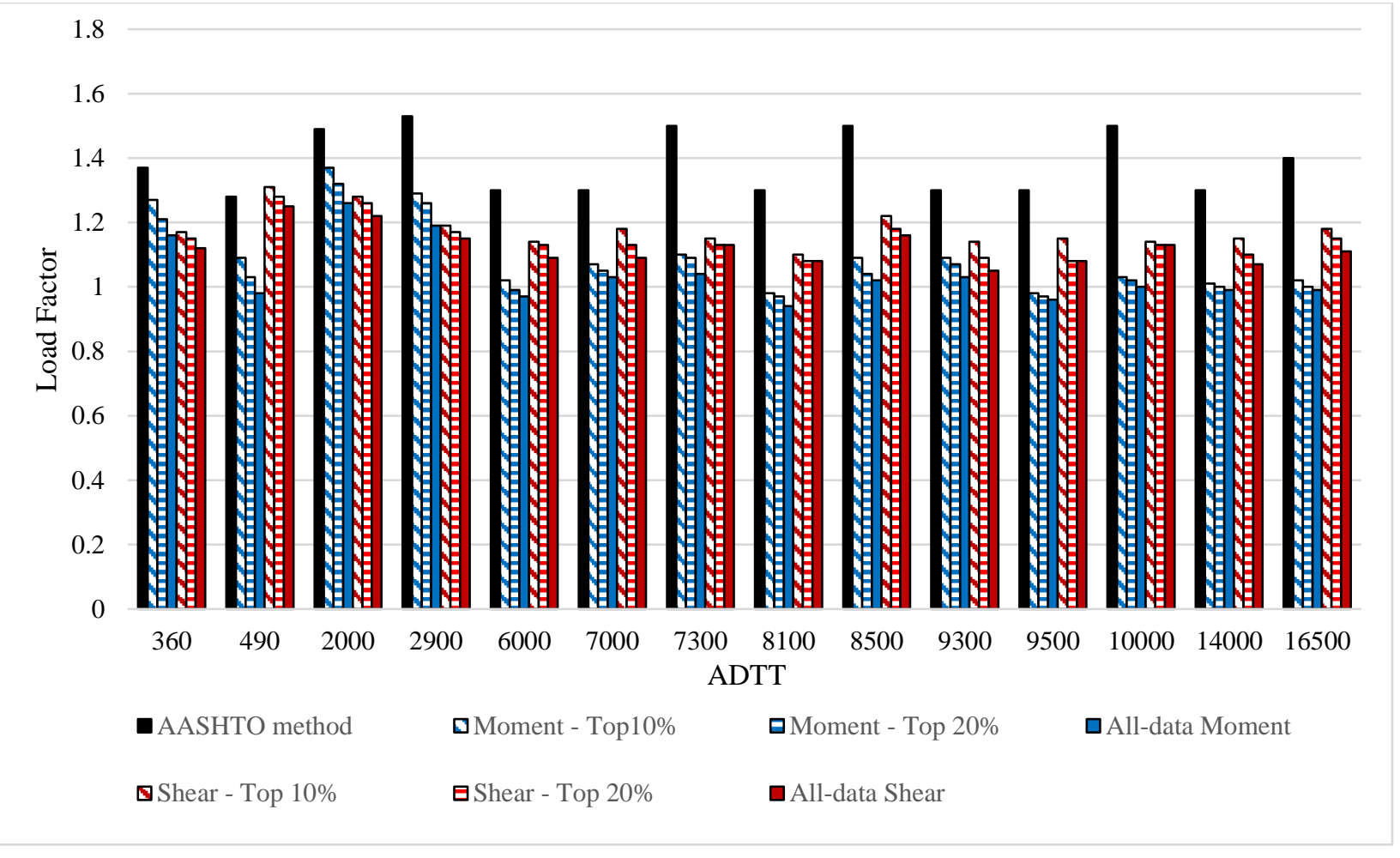

943

944

945

Figure 9. Comparison between AASHTO and Proposed Procedure, Simplified CFR.

946

947

948

949

950

951

952

953

954

955

956

957

958

959

960

961

962

963

964

965

966

967 